\title{
Relationship between Alcohol Consumption and Components of the Metabolic Syndrome in Adult Population from Maracaibo City, Venezuela
}

\author{
Valmore Bermúdez, María Sofía Martínez, Mervin Chávez-Castillo, \\ Luis Carlos Olivar, Jessenia Morillo, José Carlos Mejías, Milagros Rojas, Juan Salazar, \\ Joselyn Rojas, Roberto Añez, and Mayela Cabrera
}

Endocrine-Metabolic Research Center, "Dr. Félix Gómez”, Faculty of Medicine, University of Zulia, Maracaibo 4004, Zulia State, Venezuela

Correspondence should be addressed to Valmore Bermúdez; valmore@gmail.com

Received 20 September 2015; Revised 8 November 2015; Accepted 17 November 2015

Academic Editor: John Iskander

Copyright (C) 2015 Valmore Bermúdez et al. This is an open access article distributed under the Creative Commons Attribution License, which permits unrestricted use, distribution, and reproduction in any medium, provided the original work is properly cited.

\begin{abstract}
Introduction. Although the relationships between alcohol and disorders such as cancer and liver disease have been thoroughly researched, its effects on cardiometabolic health remain controversial. Therefore, the objective of this study was to assess the association between alcohol consumption, the Metabolic Syndrome (MS), and its components in our locality. Materials and Methods. Descriptive, cross-sectional study with randomized, multistaged sampling, which included 2,230 subjects of both genders. Two previously determined population-specific alcohol consumption pattern classifications were utilized in each gender: daily intake quartiles and conglomerates yielded by cluster analysis. MS was defined according to the 2009 consensus criteria. Association was evaluated through various multiple logistic regression models. Results. In univariate analysis (daily intake quartiles), only hypertriacylglyceridemia was associated with alcohol consumption in both genders. In multivariate analysis, daily alcohol intake $\leq 3.8 \mathrm{~g} /$ day was associated with lower risk of hypertriacylglyceridemia in females $(\mathrm{OR}=0.29$, CI 95\%: 0.09-0.86; $p=0.03$ ). Among men, subjects consuming 28.41-47.33 g/day had significantly increased risk of MS, hyperglycemia, high blood pressure, hypertriacylglyceridemia, and elevated waist circumference. Conclusions. The relationship between drinking, MS, and its components is complex and not directly proportional. Categorization by daily alcohol intake quartiles appears to be the most efficient method for quantitative assessment of alcohol consumption in our region.
\end{abstract}

\section{Introduction}

Alcohol consumption has become a widely prevalent life style in a multitude of societies and cultures, with approximately $40 \%$ of the world's population drinking regularly [1]. This behavior is in continuous expansion despite the numerous deleterious effects it bears on health, with an estimate of 2.5 million premature deaths attributed to inappropriate alcohol intake every year [2].

Although the relationships between chronic alcohol consumption and disorders such as cancer and liver disease have been thoroughly studied $[3,4]$, its cardiometabolic impact remains controversial. Various reports have found low-tomoderate alcohol intake to significantly reduce cardiovascular mortality [5] and risk of developing Type 2 Diabetes Mellitus [6], supporting a beneficial role for alcohol in this context. Nonetheless, excessive consumption has also been linked to increased risk of obesity [7], dyslipidemia [8], hyperglycemia [9], and hypertension [10], all of which are cardiovascular risk factors and components of the Metabolic Syndrome (MS).

The prevalence of MS varies largely across demographics [11], partly due to the influence of cultural factors autochthonous to each population [12]. In this regard, research assessing the relation between drinking patterns and MS prevalence 
is scarce in our locality [13]. Thus, the objective of this study was to evaluate the association between alcohol intake and MS and its individual effect on each of its components among adult subjects from Maracaibo City, Venezuela, based on previously determined population-specific alcohol consumption patterns.

\section{Materials and Methods}

2.1. Sample Selection. This report is part of the Maracaibo City Metabolic Syndrome Prevalence Study (MMSPS), a cross-sectional study whose purpose is to identify Metabolic Syndrome and cardiovascular risk factors in the adult population of the Maracaibo, the second largest city of Venezuela. The sample (1,986 individuals) was calculated based on estimations of the city's population by our National Institute of Statistics $(1,428,043$ inhabitants for the year 2007). A total of 244 subjects (12\%) were added for oversampling, in order to increase accuracy of the estimates obtained from smaller subgroups from the overall sample, amounting to a total of 2,230 individuals. Maracaibo City is divided in parishes, each of which was proportionally sampled with a multistage cluster method: In the first stage, clusters were represented by sectors from each of the 18 parishes, selecting 4 from each parish by simple randomized sampling. In the second phase, clusters were represented by city blocks within each sector, which were selected by simple randomized sampling using a random number generation tool. From the overall population, 2,026 individuals were selected on the basis of availability of insulin determination. Further details of the sampling process have been previously published elsewhere [14].

2.2. Ethical Considerations. All individuals enrolled in the study signed a written informed consent before undergoing physical examination and blood sample collection. All procedures were approved by the Ethics Committee of the Endocrine and Metabolic Diseases Research Center of The University of Zulia, Maracaibo, Venezuela.

2.3. Subject Evaluation. Data were collected through completion of a full clinical record carried out by trained personnel, which included interrogation regarding personal and family medical history, with an emphasis on current or past acute or chronic liver disease. Likewise, ethnic origin, educational status, occupational status, tobacco use, and socioeconomic status, according to the Graffar scale modified by Méndez Castellano and de Méndez [15], were also investigated. The Long Form of the International Physical Activity Questionnaire (IPAQ-LF) was used for the evaluation of physical activity; its design allows for the assessment of PA in four domains: work, transportation, leisure, and household activities.

2.4. Alcohol Consumption and Drinking Patterns. For the assessment of alcohol intake, subjects were asked to estimate the amount of alcoholic drinks they consumed within a month, with the approximate quantity and frequency of daily intake for each type of drink: beer, spirits, and wine and its derivatives. Accounting for the standard content of alcohol grams in each kind of beverage [16], daily intake of alcohol grams was calculated through the formula [17]:

$$
\frac{\text { Daily Consumed }(\mathrm{mL}) \times \text { Degrees of Alcohol } \times 0.8}{100},
$$

where 0.8 is a constant which represents ethanol density in drinks. Based on this estimation, "habitual drinkers" were defined as subjects who consumed $\geq 1$ gram of alcohol daily [18]. These individuals were then categorized by two distinct methods previously described in our report evaluating drinking patterns in Maracaibo city [19]:

(1) Gender-specific quartiles of alcohol grams consumed daily (25th percentile, 50th percentile, and 75th percentile).

(2) Three gender-specific conglomerate categories obtained from two-staged cluster analysis, which allows separation of patterns into clusters, sets, or groups, according to distance criteria (Figure 1). This technique was used to include quantity and type of alcohol beverage (beer, wine, and spirit drinks); in order to evaluate the quality of the resulting clusters, the cohesion, separation, and silhouette coefficient were calculated.

2.5. Evaluation of Blood Pressure. Blood pressure (BP) was taken with subjects sitting down with their feet on the floor following 15 minutes of rest, determined through the auscultatory method with a calibrated mercury sphygmomanometer, identifying Korotkoff's phases I and V as systolic and diastolic BP, respectively. BP was determined 3 times, with 15 minutes in between each take, on two different days.

2.6. Anthropometric Assessment. Waist circumference (WC) was measured using calibrated measuring tapes in accordance with the anatomical landmarks proposed by the USA National Institutes of Health protocol [20]. Height was obtained using a calibrated rod, millimeters and centimeters, with the patient barefooted and his/her back facing the wall. Weight was recorded using a digital scale (Tanita, TBF-310 GS Body Composition Analyzer, Tokyo, Japan) with the patient using light clothing and no shoes. Body Mass Index (weight/height ${ }^{2}$ ) was expressed in $\mathrm{kg} / \mathrm{m}^{2}$.

2.7. Laboratory Analysis. Overnight fasting determination of glucose, total cholesterol, triacylglycerides (TAG), and HDL$\mathrm{C}$ was done with an automated analyzer (Human Gesellschaft für Biochemica und Diagnostica $\mathrm{mbH}$, Germany); the intraassay variation coefficients for total cholesterol, TAG, and HDL-C were $3 \%, 5 \%$, and $5 \%$, respectively. LDL-C and VLDL-C levels were calculated applying Friedewald's formula [21] when TAG levels were $<400 \mathrm{mg} / \mathrm{dL}$. With TAG levels above this cutoff, LDL-C concentrations were measured through lipoprotein electrophoresis and densitometry with BioRad GS-800 (BioRad). 


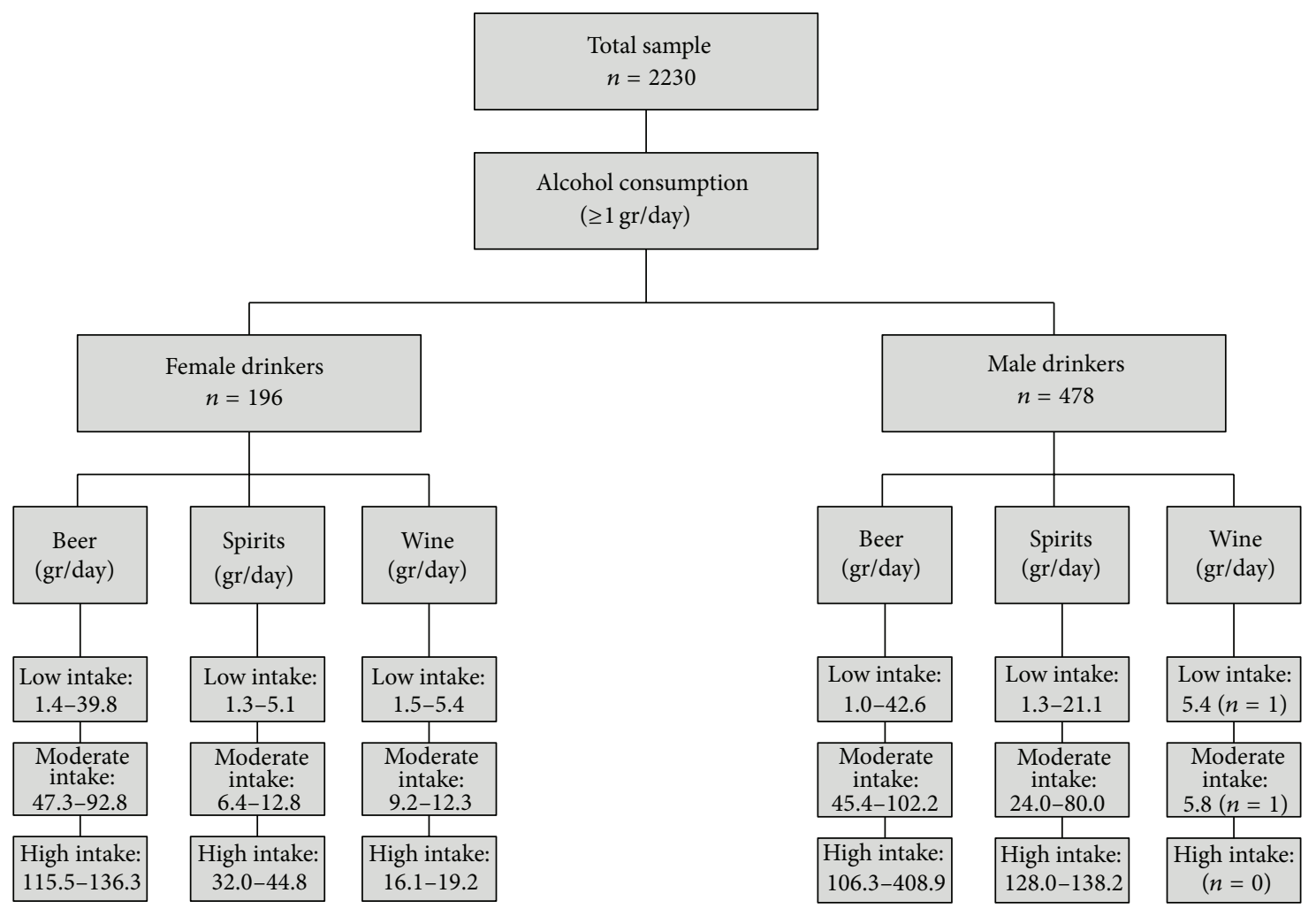

FIGURE 1: Diagram showing the processing of the sample applying two-staged cluster analysis for categorizing subjects according to gender, type of beverage, and daily alcohol intake. Maracaibo, 2015.

2.8. Diagnosis of Metabolic Syndrome. MS was diagnosed using the criteria from the IDF/AHA/NHLBI-2009 consensus [22], which requires the presence of $\geq 3$ of the following components: (a) low HDL-C, $<50 \mathrm{mg} / \mathrm{dL}$ in females or $<40 \mathrm{mg} / \mathrm{dL}$ in males; (b) high TAG, $\geq 150 \mathrm{mg} / \mathrm{dL}$; (c) elevated $\mathrm{WC}, \geq 80 \mathrm{~cm}$ in females or $\geq 90 \mathrm{~cm}$ in males; (d) hyperglycemia, fasting glycemia $\geq 100 \mathrm{mg} / \mathrm{dL}$, or personal history of DM2 or prescription of hypoglycemic drugs; and (e) high blood pressure, $\mathrm{BP} \geq 130 / 85 \mathrm{~mm} / \mathrm{Hg}$ or previously diagnosed hypertension or prescription of antihypertensive drugs.

2.9. Statistical Analysis. Qualitative variables were expressed as absolute and relative frequencies and were assessed for associations with Pearson's Chi-squared $\left(\chi^{2}\right)$ test. Qualitative variables were evaluated for distribution normality with Geary's test and were expressed as arithmetic means \pm standard deviation. One-way ANOVA was used to evaluate differences between means from $\geq 3$ groups, with post hoc Tukey analysis in cases with statistical significance. Variables with nonnormal distribution, such as daily alcohol intake, were expressed as medians (25th percentile-75th percentile). Various gender-specific multiple logistic regression models were constructed in order to estimate odds ratios (95\% CI) for the presence of MS and each of its separate components, adjusting for age groups, ethnic groups, socioeconomic status, educational status, occupational status, family history of hypertension and diabetes, tobacco use, four domains of physical activity, and both categorizations for drinking patterns (quartiles of alcohol grams consumed daily and conglomerates from cluster analysis). Data were analyzed with the Statistical Package for the Social Sciences (SPSS) v. 21 for Windows (IBM Inc. Chicago, IL). Results were considered statistically significant when $p<0.05$.

\section{Results}

3.1. Prevalence of Metabolic Syndrome and Alcohol Consumption. A total of 2,230 subjects were studied (52.6\% females, $n=1,172$ ), with a mean age of $39.3 \pm 15.4$ years. General characteristics of the population are shown in Table 1. Table 2 shows the prevalence of MS by gender and quartiles of daily alcohol intake. Among women, MS prevalence increases progressively across quartiles, with the greatest consumption in the fourth quartile $(\geq 28.41 \mathrm{~g} /$ day $)(42.5 \%, n=17$; $\left.\chi^{2}=9.332 ; p=0.053\right)$. In men, the greatest prevalence of MS was in the group consuming 28.41-47.33 g/day, with $55.1 \%(n=49)$, with no statistically significant association between these variables.

On the other hand, Table 3 displays the prevalence of MS by gender and drinking pattern conglomerates. In females, MS prevalence appears to increase across categories (low intake: $31.9 \%$ versus high intake: $55.6 \% ; \chi^{2}=6.372 ; p=$ 0.095). In males, MS prevalence was similar in the groups with moderate and high intake $\left(50 \% ; \chi^{2}=3.166 ; p=0.367\right)$. 
TABLE 1: Characteristics of general population by gender. Maracaibo, 2015.

\begin{tabular}{|c|c|c|c|c|c|c|}
\hline & \multicolumn{2}{|c|}{$\begin{array}{l}\text { Females } \\
n=1172\end{array}$} & \multicolumn{2}{|c|}{$\begin{array}{c}\text { Males } \\
n=1058\end{array}$} & \multicolumn{2}{|c|}{$\begin{array}{c}\text { Total } \\
n=2230\end{array}$} \\
\hline & $n$ & $\%$ & $n$ & $\%$ & $n$ & $\%$ \\
\hline \multicolumn{7}{|l|}{ Age groups (years) } \\
\hline $18-29$ & 349 & 29.8 & 413 & 39.0 & 762 & 34.2 \\
\hline $30-44$ & 325 & 27.7 & 297 & 28.1 & 622 & 27.9 \\
\hline $45-59$ & 346 & 29.5 & 259 & 24.5 & 605 & 27.1 \\
\hline$\geq 60$ & 152 & 13.0 & 89 & 8.4 & 241 & 10.8 \\
\hline \multicolumn{7}{|l|}{ Ethnic groups } \\
\hline Mixed & 876 & 74.7 & 816 & 77.1 & 1692 & 75.9 \\
\hline Hispanic white & 191 & 16.3 & 161 & 15.2 & 352 & 15.8 \\
\hline Afro-Venezuelan & 30 & 2.6 & 36 & 3.4 & 66 & 3.0 \\
\hline Amerindian & 62 & 5.3 & 44 & 4.2 & 106 & 4.8 \\
\hline Others & 13 & 1.1 & 1 & 0.1 & 14 & 0.6 \\
\hline \multicolumn{7}{|l|}{ Alcohol intake quartiles } \\
\hline Nondrinkers & 976 & 83.3 & 582 & 55.0 & & \\
\hline Quartile 1 & 53 & 4.5 & 119 & 11.2 & - & - \\
\hline Quartile 2 & 45 & 3.8 & 145 & 13.7 & - & - \\
\hline Quartile 3 & 58 & 4.9 & 89 & 8.4 & - & - \\
\hline Quartile 4 & 40 & 3.4 & 123 & 11.6 & - & - \\
\hline \multicolumn{7}{|c|}{ Alcohol intake pattern (conglomerates) } \\
\hline Nondrinkers & 976 & 83.3 & 580 & 54.8 & - & - \\
\hline Low intake & 160 & 13.7 & 328 & 31.0 & - & - \\
\hline Moderate intake & 27 & 2.3 & 124 & 11.7 & - & - \\
\hline High intake & 9 & 0.8 & 26 & 2.5 & - & - \\
\hline Metabolic Syndrome ${ }^{\dagger}$ & 474 & 40.4 & 472 & 44.6 & 946 & 42.4 \\
\hline High blood pressure $^{\dagger}$ & 410 & 35.0 & 456 & 43.1 & 866 & 38.8 \\
\hline Hyperglycemia $^{\dagger}$ & 301 & 25.7 & 322 & 30.4 & 623 & 27.9 \\
\hline Low HDL-C $\mathrm{C}^{\dagger}$ & 752 & 64.2 & 536 & 50.7 & 1288 & 57.8 \\
\hline High triacylglycerides $^{\dagger}$ & 269 & 23.0 & 347 & 32.8 & 616 & 27.6 \\
\hline Abdominal obesity $^{\dagger}$ & 926 & 79.0 & 749 & 70.8 & 1675 & 75.1 \\
\hline \multicolumn{7}{|c|}{ Body Mass Index classification $\left(\mathrm{kg} / \mathrm{m}^{2}\right)$} \\
\hline$<24.9$ & 420 & 35,8 & 275 & 26,0 & 695 & 31,2 \\
\hline $25.0-29.9$ & 371 & 31,7 & 415 & 39,2 & 786 & 35,2 \\
\hline$\geq 30.0$ & 381 & 32,5 & 368 & 34,8 & 749 & 33,6 \\
\hline
\end{tabular}

3.2. Components of the Metabolic Syndrome and Alcohol Consumption. When assessing the association between separate MS components and quartiles of daily alcohol intake (Table 4), we found a progressive increase in the prevalence of hypertriacylglyceridemia with higher consumption in women (<3.80 g/day: $7.5 \%, n=4$ versus $\geq 28.41 \mathrm{~g} /$ day: $25 \%$, $\left.n=10 ; \chi^{2}=9.600 ; p=0.04\right)$. In contrast, among men there was no clear trend regarding alcohol intake quartiles and MS components, although hypertriacylglyceridemia was the most closely linked factor for this categorization $\left(\chi^{2}=9.794\right.$, $p=0.04)$.

In consonance, evaluation of the association between the conglomerate classification and MS components revealed hypertriacylglyceridemia to show the greatest degree of association, progressively increasing in prevalence across groups (low intake: $13.8 \%, n=22$ versus high intake: $44.4 \%, n=4$; $\left.\chi^{2}=10.980 ; p=0.01\right)$. No other components showed a significant association with this categorization in females; and no link was found between these clusters and any MS components in males (Table 5).

3.3. Serum Triacylglycerides and Alcohol Consumption. Figure 2 illustrates the epidemiologic behavior of serum TAG levels by gender and daily alcohol intake quartiles. Women in the $<3.8 \mathrm{~g} /$ day group had significantly lower TAG than nondrinkers (86.2 $\pm 43.5 \mathrm{mg} / \mathrm{dL}$ versus $120.1 \pm 91.9 \mathrm{mg} / \mathrm{dL}$, resp.; $p=0.046)$. No significant differences were found concerning TAG levels and daily alcohol intake quartiles in men.

On the other hand, Figure 3 depicts the behavior of serum TAG concentration by gender and drinking pattern clusters. 


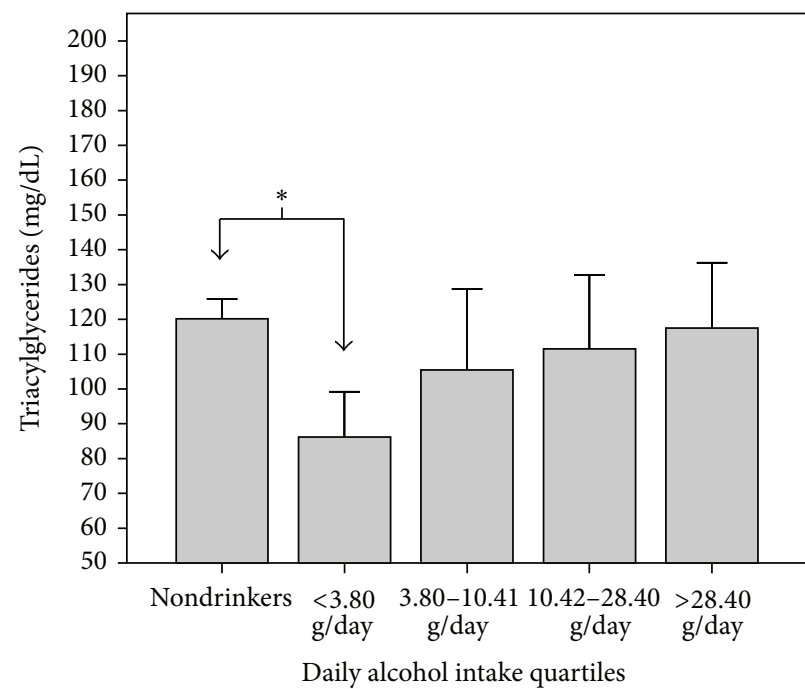

(a) Females

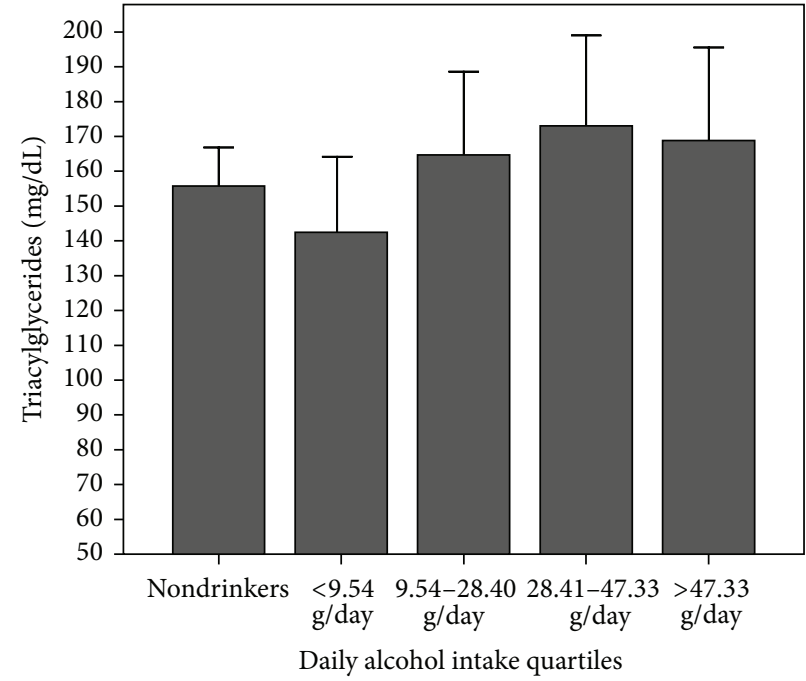

(b) Males

FIGURE 2: Serum triacylglyceride concentration by gender and daily alcohol intake quartiles. Maracaibo, 2015. * One-way ANOVA. Post hoc Tukey: $p=0.046$.

TABle 2: Prevalence of Metabolic Syndrome by gender and daily alcohol intake quartiles. Maracaibo, 2015.

\begin{tabular}{|c|c|c|c|}
\hline & \multicolumn{2}{|c|}{ With Metabolic Syndrome } & \multirow{2}{*}{$\chi^{2}(p)^{*}$} \\
\hline & $n$ & $\%$ & \\
\hline Females & & & $9.332(0.053)$ \\
\hline Nondrinkers & 407 & 41.7 & \\
\hline$<3.80 \mathrm{~g} /$ day & 12 & 22.6 & \\
\hline $3.80-10.41 \mathrm{~g} /$ day & 14 & 31.1 & \\
\hline $10.42-28.40 \mathrm{~g} /$ day & 24 & 41.4 & \\
\hline$\geq 28.41 \mathrm{~g} /$ day & 17 & 42.5 & \\
\hline Males & & & $6.763(0.149)$ \\
\hline Nondrinkers & 247 & 42.4 & \\
\hline$<9.54 \mathrm{~g} /$ day & 49 & 41.2 & \\
\hline $9.54-28.40 \mathrm{~g} / \mathrm{day}$ & 71 & 49.0 & \\
\hline $28.41-47.33 \mathrm{~g} / \mathrm{day}$ & 49 & 55.1 & \\
\hline$\geq 47.34 \mathrm{~g} /$ day & 56 & 45.5 & \\
\hline
\end{tabular}

${ }^{*}$ Pearson's Chi-squared test.

Females in the low-intake conglomerate had lower TAG than nondrinkers, without statistical significance (101.2 \pm $53.9 \mathrm{mg} / \mathrm{dL}$ versus $120.1 \pm 91.99 \mathrm{mg} / \mathrm{dL}$, resp.; $p=0.053)$. Among males, individuals in the high-intake conglomerate had significantly higher TAG $(210.17 \pm 192.58 \mathrm{mg} / \mathrm{dL})$ than those in the low and moderate-intake groups.

3.4. Alcohol Consumption and Risk of Metabolic Syndrome and Its Components. Multivariate analysis of the relationship between drinking and MS and its components indicated hypertriacylglyceridemia to be the most tightly associated with this life style in females. Indeed, in this gender, analysis by daily alcohol intake quartiles (Table 6 ) showed subjects in the group with $<3.80 \mathrm{~g} /$ day to have a lower risk of hypertriacylglyceridemia than nondrinkers $(\mathrm{OR}=0.29$, CI 95\%: $0.09-086 ; p=0.03$ ). Likewise, analysis by clusters also demonstrated low-intake drinkers to have a lower risk of elevated TAG levels than nondrinkers $(\mathrm{OR}=0.50, \mathrm{CI} 95 \%$ : $0.29-0.84 ; p=0.01$ ), while those with higher consumption showed higher risk for MS and high TAG (Table 7).

Meanwhile, in males, multivariate analysis by daily alcohol intake quartiles (Table 8) found individuals in the 28.41$47.33 \mathrm{~g} /$ day category to have a greater risk of MS, hyperglycemia, elevated WC, high blood pressure, and high TAG, whereas those consuming $\geq 47.34 \mathrm{~g} /$ day had a reduced risk of low HDL-C (OR = 0.52, CI 95\%: 0.34-0.79; $p<0.01)$. Finally, in men, analysis by conglomerates found high-intake drinkers to be associated with hyperglycemia $(\mathrm{OR}=3.18$; CI 95\%: 1.25-8.14; $p=0.02$ ) and moderate-intake drinkers to be associated with Low HDL-C and high blood pressure (Table 9).

\section{Discussion}

Psychobiologic life styles play an indisputable role in global well-being and are particularly prominent in the development of cardiometabolic alterations, with diet, physical activity, smoking, and alcohol consumption attracting vast scientific attention in recent decades [23]. Although elements such as physical inactivity and hypercaloric diets are regarded as largely ubiquitous westernized lifestyles propagated by mass globalization [24], drinking patterns tend to be dictated by population-specific geographic, sociodemographic, and cultural factors [1]. Therefore, it is important to analyze these characteristics in each population and their individual and/or accumulative relation to cardiometabolic disorders. Numerous studies have described the influence of alcohol consumption on the prevalence of MS, with a large part of 
TABLE 3: Prevalence of Metabolic Syndrome by gender and drinking pattern conglomerates. Maracaibo, 2015.

\begin{tabular}{|c|c|c|c|}
\hline & \multicolumn{2}{|c|}{ With Metabolic Syndrome } & \multirow{2}{*}{$\chi^{2}(p)^{*}$} \\
\hline & $n$ & $\%$ & \\
\hline Females (gr/day) & & & $6.372(0.095)$ \\
\hline Nondrinkers & 407 & 41.7 & \\
\hline Low intake (1.28-39.76) & 51 & 31.9 & \\
\hline Moderate intake (6.40-92.77) & 11 & 40.7 & \\
\hline High intake (16.13-136.32) & 5 & 55.6 & \\
\hline Males (gr/day) & & & $3.166(0.367)$ \\
\hline Nondrinkers & 246 & 42.4 & \\
\hline Low intake $(1.00-42.60)$ & 151 & 46.0 & \\
\hline Moderate intake (5.76-102.24) & 62 & 50.0 & \\
\hline High intake (106.03-408.96) & 13 & 50.0 & \\
\hline
\end{tabular}

${ }^{*}$ Pearson's Chi-squared test.

TABLE 4: Prevalence of Metabolic Syndrome components by gender and daily alcohol intake quartiles. Maracaibo, 2015.

\begin{tabular}{|c|c|c|c|c|c|c|c|c|c|c|}
\hline & \multicolumn{2}{|c|}{ Hyperglycemia } & \multicolumn{2}{|c|}{ Low HDL-C } & \multicolumn{2}{|c|}{ Elevated waist circumference } & \multicolumn{2}{|c|}{ High blood pressure } & \multicolumn{2}{|c|}{ High TAG } \\
\hline & $n$ & $\%$ & $n$ & $\%$ & $n$ & $\%$ & $n$ & $\%$ & $n$ & $\%$ \\
\hline \multicolumn{11}{|l|}{ Females } \\
\hline Nondrinkers & 253 & 25.9 & 635 & 65.1 & 769 & 78.8 & 354 & 36.3 & 236 & 24.2 \\
\hline$<3.80$ g/day & 11 & 20.8 & 28 & 52.8 & 37 & 69.8 & 14 & 26.4 & 4 & 7.5 \\
\hline $3.80-10.41 \mathrm{~g} /$ day & 13 & 28.9 & 29 & 64.4 & 37 & 82.2 & 8 & 17.8 & 7 & 15.6 \\
\hline $10.42-28.40 \mathrm{~g} /$ day & 14 & 24.1 & 35 & 60.3 & 50 & 86.2 & 20 & 34.5 & 12 & 20.7 \\
\hline$\geq 28.41 \mathrm{~g} /$ day & 10 & 25.0 & 25 & 62.5 & 33 & 82.5 & 14 & 35.0 & 10 & 25.0 \\
\hline \multicolumn{11}{|l|}{ Males } \\
\hline Nondrinkers & 165 & 28.4 & 305 & 52.4 & 402 & 69.1 & 244 & 41.9 & 176 & 30.2 \\
\hline$<9.54$ g/day & 38 & 31.9 & 58 & 48.7 & 87 & 73.1 & 49 & 41.2 & 33 & 27.7 \\
\hline $9.54-28.40 \mathrm{~g} / \mathrm{day}$ & 41 & 28.3 & 76 & 52.4 & 108 & 74.5 & 64 & 44.1 & 56 & 38.6 \\
\hline $28.41-47.33$ g/day & 37 & 41.6 & 46 & 51.7 & 70 & 78.7 & 46 & 51.7 & 38 & 42.7 \\
\hline$>47.33 \mathrm{~g} /$ day & 41 & 33.3 & 51 & 41.5 & 82 & 66.7 & 53 & 43.1 & 44 & 35.8 \\
\hline
\end{tabular}

HDL-C: High-Density Lipoprotein-Cholesterol. TAG: triacylglycerides.

Pearson's Chi-squared test $(p)$ :

Females: hyperglycemia: $\chi^{2}(p)=1.028(0.90)$; low HDL-C: $\chi^{2}(p)=3.720(0.44)$; elevated waist circumference: $\chi^{2}(p)=5.118(0.27)$; high blood pressure: $\chi^{2}$ $(p)=8.285(0.08)$; high TAG: $\chi^{2}(p)=9.600(0.04)$.

Males: hyperglycemia: $\chi^{2}(p)=7.343(0.11)$; low HDL-C: $\chi^{2}(p)=5.263(0.26)$; elevated waist circumference: $\chi^{2}(p)=5.768(0.21)$; high blood pressure: $\chi^{2}(p)$ $=3.246$ (0.51); high TAG: $\chi^{2}(p)=9.794(0.04)$.

these delineating a direct relationship between drinking and this condition $[25,26]$. However, this is not a universal finding $[13,27]$, as evidenced in this study, even when utilizing two distinct classification systems for alcohol intake.

Initially, alcohol consumption was evaluated in quartiles according to sex but not taking into account the beverage consumed by the subjects. Later, a cluster analysis according to sex was calculated adding the daily quantity of alcohol consumption per beverage [19]. Interestingly, although quartile categorization yields evenly distributed groups, cluster analysis allows the delimitation of smaller-sized groups with alcohol intake much greater than that of habitual drinkers. This methodological heterogeneity varies according to daily consumption quantities which are influenced by several factors, including sociocultural norm, type of alcohol consumed, and dietary behavior. This discrepancy is important when analyzing nonsignificant results $a$ priori.

We have ascertained a lower prevalence of MS in female subjects with low alcohol intake, in concordance with the findings of Lee et al. [28], who determined MS prevalence to be reduced among women with low or moderate consumption in their population. Furthermore, Wakabayashi [29] has described females with low alcohol intake to have lower MS prevalence than nondrinkers; and Freiberg et al. [30] have reported low-moderate drinkers to have lower MS prevalence ( $47 \%$ in females, $48 \%$ in males) in comparison to nondrinkers, independent of ethnic origin.

When individually studying clinical-metabolic alterations, we found hypertriacylglyceridemia to behave similarly to MS, again in the female gender. This trend echoes 
TABLE 5: Prevalence of Metabolic Syndrome components by gender and drinking pattern conglomerates. Maracaibo, 2015.

\begin{tabular}{|c|c|c|c|c|c|c|c|c|c|c|}
\hline & \multicolumn{2}{|c|}{ Hyperglycemia } & \multicolumn{2}{|c|}{ Low HDL-C } & \multicolumn{2}{|c|}{ Elevated waist circumference } & \multicolumn{2}{|c|}{ High blood pressure } & \multicolumn{2}{|c|}{ High TAG } \\
\hline & $n$ & $\%$ & $n$ & $\%$ & $n$ & $\%$ & $n$ & $\%$ & $n$ & $\%$ \\
\hline \multicolumn{11}{|l|}{ Females (gr/day) } \\
\hline Nondrinkers & 253 & 25.9 & 635 & 65.1 & 769 & 78.8 & 354 & 36.3 & 236 & 24.2 \\
\hline Low intake (1.28-39.76) & 40 & 25.0 & 93 & 58.1 & 125 & 78.1 & 44 & 27.5 & 22 & 13.8 \\
\hline Moderate intake (6.40-92.77) & 7 & 25.9 & 19 & 70.4 & 24 & 88.9 & 9 & 33.3 & 7 & 25.9 \\
\hline High intake (16.13-136.32) & 1 & 11.1 & 5 & 55.6 & 8 & 88.9 & 3 & 33.3 & 4 & 44.4 \\
\hline \multicolumn{11}{|l|}{ Males (gr/day) } \\
\hline Nondrinkers & 165 & 28.4 & 304 & 52.4 & 401 & 69.1 & 242 & 41.7 & 176 & 30.3 \\
\hline Low intake (1.00-42.60) & 102 & 31.1 & 165 & 50.3 & 243 & 74.1 & 143 & 43.6 & 113 & 34.5 \\
\hline Moderate intake (5.76-102.24) & 42 & 33.9 & 56 & 45.2 & 84 & 67.7 & 60 & 48.4 & 46 & 37.1 \\
\hline High intake (106.03-408.96) & 13 & 50.0 & 11 & 42.3 & 21 & 80.8 & 11 & 42.3 & 12 & 46.2 \\
\hline
\end{tabular}

HDL-C: High-Density Lipoprotein-Cholesterol. TAG: triacylglycerides.

Pearson's Chi-squared test $(p)$ :

Females: hyperglycemia: $\chi^{2}(p)=1.070(0.78)$; low HDL-C: $\chi^{2}(p)=3.622(0.30)$; elevated waist circumference: $\chi^{2}(p)=2.222(0.52)$; high blood pressure: $\chi^{2}$ $(p)=4.693(0.19)$; high TAG: $\chi^{2}(p)=10.980(0.01)$.

Males: hyperglycemia: $\chi^{2}(p)=6.542(0.08)$; low HDL-C: $\chi^{2}(p)=2.956(0.39)$; elevated waist circumference: $\chi^{2}(p)=4.298(0.23)$; high blood pressure: $\chi^{2}$ $(p)=1.901(0.59)$; high TAG: $\chi^{2}(p)=5.13(0.16)$.

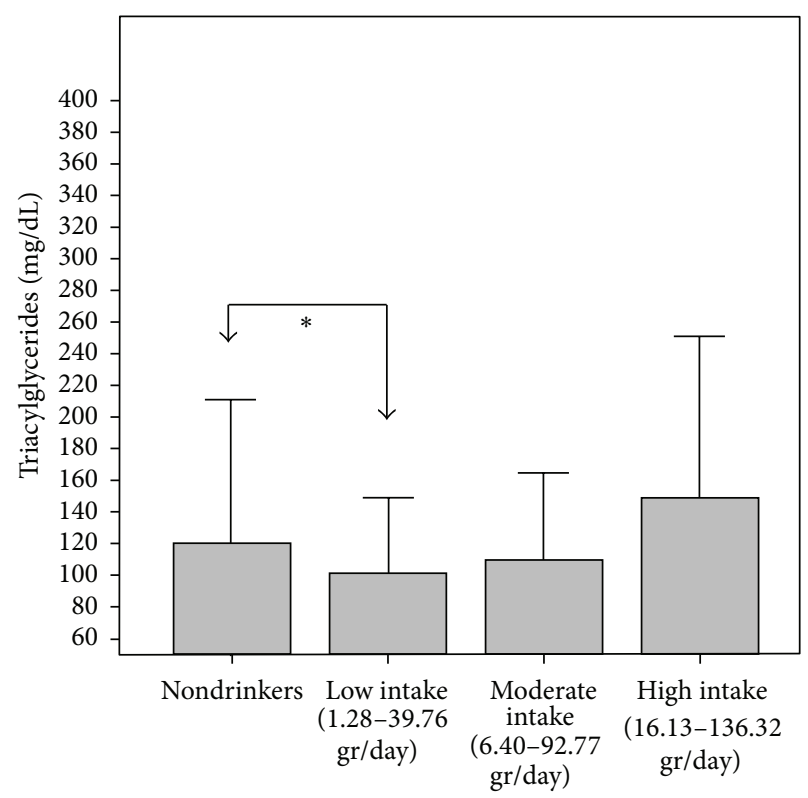

(a) Females

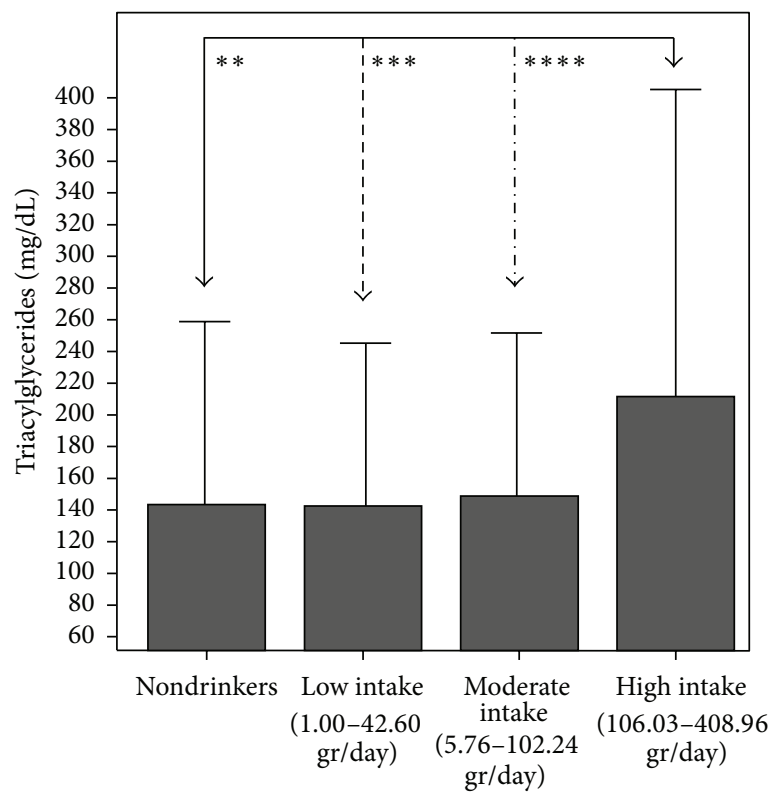

(b) Males

FIGURE 3: Serum triacylglyceride concentration by gender and drinking patter conglomerates. Maracaibo, 2015. One-way ANOVA. Post hoc Tukey: ${ }^{*} p=0.053,{ }^{* *} p=0.017,{ }^{* * *} p=0.016,{ }^{* * * *} p=0.05$.

the results of the ATTICA study, where, after a 10-year follow-up, moderate alcohol consumption (1-2 drinks/day) was associated with decreased incidence of high TAG [31]. This phenomenon has been suggested to be related to the fact that low-intake drinkers predominantly consume wine, instead of beer and spirit drinks; thus, the bioflavonoids in this beverage may be responsible for this protective effect [32].

Multivariate analysis further supports this finding in women, with the impact of drinking confined to serum TAG concentration. Indeed, low alcohol consumption appeared to act as a protective factor when studied through daily intake quartiles, similar to the results of Clerc et al. [33], who attributed this finding to complex interplay between alcohol, carbohydrate and lipoprotein metabolism, insulin secretion, and energetic balance. Conversely, we observed that high intake acts as a risk factor for high TAG as well as for MS when evaluated through drinking pattern conglomerates. These results are in agreement with a report by Chen et al. [34], who determined consumption of $\geq 10 \mathrm{~g} /$ day to be associated with hypertriacylglyceridemia. Therefore, although our results 


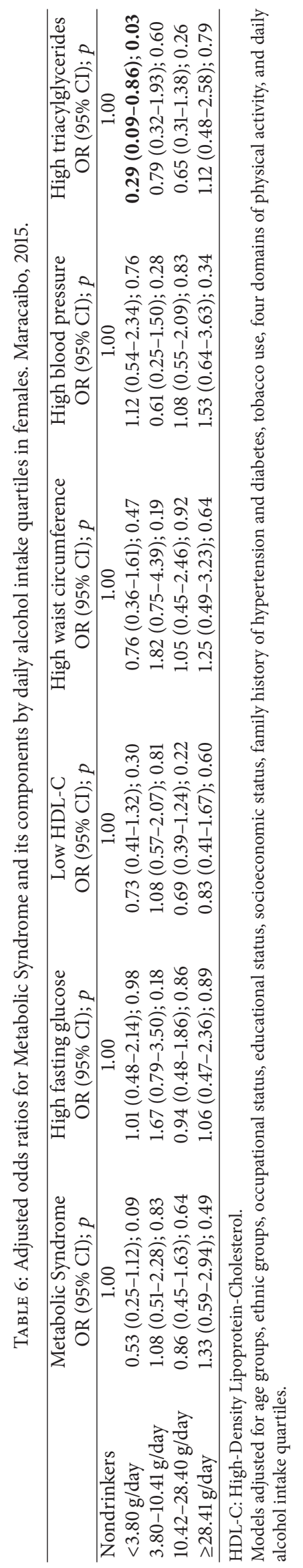




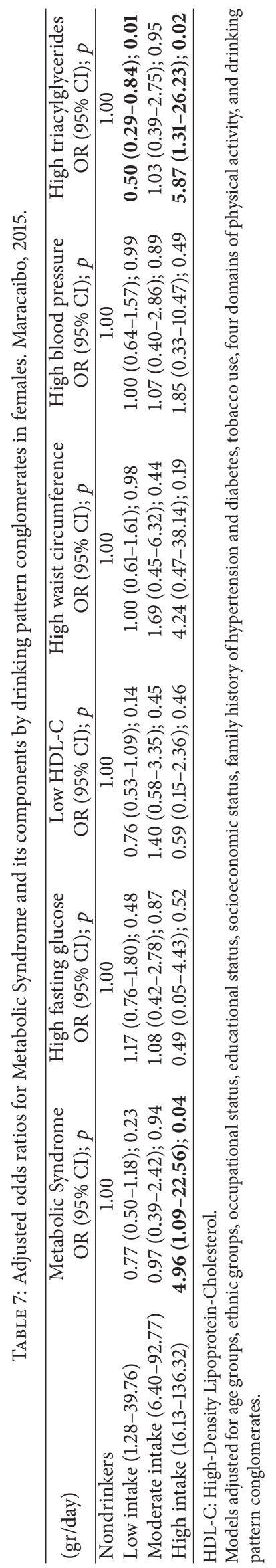




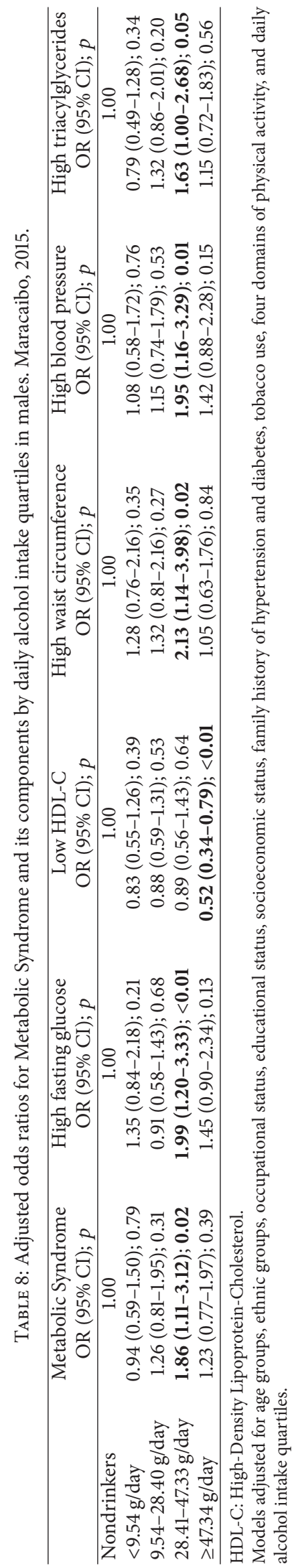




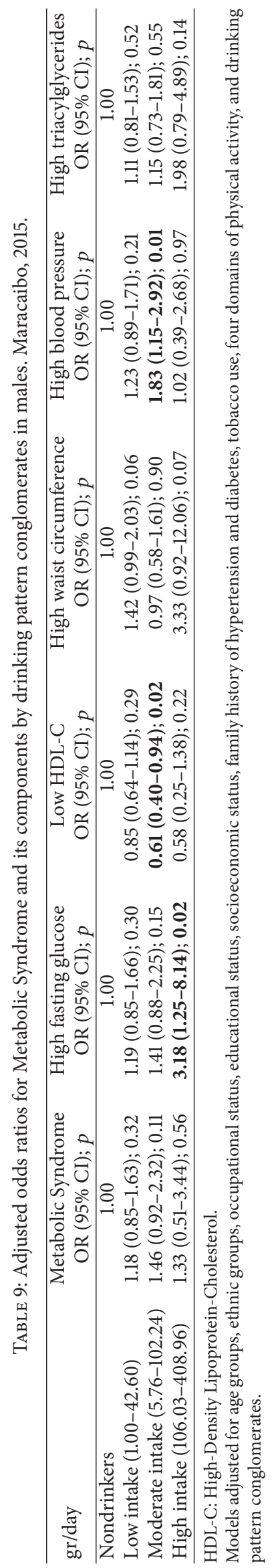


differed depending on which classification was applied, both systems delineate a similar behavior for alcohol and serum TAG levels in women.

In contrast, in men, univariate analysis revealed a weak or absent degree of statistical association between drinking and MS or its components. Nonetheless, multivariate assessment yielded significant results concerning the group consuming 28.41-47.33 g/day (third quartile of daily intake), who displayed increased risk of MS. This concurs with observations in 19,000 Chinese subjects, although these were exclusive wine consumers [35]. In our study, individuals in this group also exhibited a greater risk of high blood pressure, as previously stated in a meta-analysis comprising 156 studies on the relationship between alcohol and this disorder [36]. Also in this group, drinking was strongly associated with hyperglycemia, almost doubling the risk of nondrinkers for this condition, resembling findings in an elderly Italian population. This effect has been proposed to be due to enhanced peripheral insulin sensitivity in response to moderate drinking, which is lost with greater quantities of alcohol [37].

Our finding of $\geq 47.34 \mathrm{gr} /$ day intake or moderate intake by conglomerates acting as a protective factor for low HDL-C is consistent with reports from studies with differing methodology and drinking patterns: The Cooper Center Longitudinal Study, realized in 3,000 healthy American subjects, showed men with high consumption to have the highest HDL-C values $(55.9 \pm 11.3 \mathrm{mg} / \mathrm{dL})$, while nondrinkers and low-intake drinkers displayed greater risk for this dyslipidemia [38]. Similarly, in a meta-analysis, Brien et al. [39] ascertained an ascending dose-response relationship between the quantity of alcohol consumed and HDL-C levels. Future research should explore whether the effect of alcohol on this lipoprotein influences cardiovascular outcomes, the antiatherogenic properties and functionality of these molecules in this scenario, and the potential impact of the daily drinking of these quantities of alcohol in other organ systems [40].

The limitations of this study include its cross-sectional design which hinders the possibility of determining causality relationships and the lack of nutritional data which might add another measure of influence over alcohol consumption frequency and quantity. Currently, this branch of research is being conducted as part of the MMSPS, which will render the necessary data to answer this important inquiry, especially in light of MS risk.

Finally, it is important to highlight that in our population the protective effect of alcohol against high TAG in women appears to occur with daily intake quantities equal to less than half the standard measures of the main alcoholic beverages in our locality. On the other hand, in men, the effects of alcohol on MS and its components are apparent with daily quantities equal to 4-6 beers, 3-5 spirit drinks, or 4-7 glasses of wine. These values should be utilized by clinicians as reference for educational efforts regarding the role of this substance in cardiometabolic health in our community. We also support evaluation by daily intake quartiles as the most easily applicable and reproducible method for quantitative assessment of this practice in our region, never forgetting to take into account those subjects with high alcohol intake.

\section{Conflict of Interests}

The authors have no conflict of interests to disclose.

\section{Acknowledgments}

This work was supported by Research Grant no. CC-0437-1021-09-10 from CONDES, University of Zulia, and Research Grant no. FZ-0058-2007 from Fundacite Zulia.

\section{References}

[1] K. D. Shield, M. Rylett, G. Gmel, G. Gmel, T. A. K. Kehoe-Chan, and J. Rehm, "Global alcohol exposure estimates by country, territory and region for 2005-a contribution to the Comparative Risk Assessment for the 2010 Global Burden of Disease Study," Addiction, vol. 108, no. 5, pp. 912-922, 2013.

[2] WHO, Global Status Report on Alcohol and Health 2011, http:// www.who.int/substance_abuse/publications/global_alcohol_report/msbgsruprofiles.pdf.

[3] R. E. Mann, R. G. Smart, and R. Govoni, "The epidemiology of alcoholic liver disease," Alcohol Research and Health, vol. 27, no. 3, pp. 209-219, 2003.

[4] H. K. Seitz and F. Stickel, "Molecular mechanisms of alcoholmediated carcinogenesis," Nature Reviews Cancer, vol. 7, no. 8, pp. 599-612, 2007.

[5] V. G. Athyros, E. N. Liberopoulos, D. P. Mikhailidis et al., "Association of drinking pattern and alcohol beverage type with the prevalence of metabolic syndrome, diabetes, coronary heart disease, stroke, and peripheral arterial disease in a Mediterranean cohort," Angiology, vol. 58, no. 6, pp. 689-697, 2008.

[6] L. Shi, X.-O. Shu, H. Li et al., "Physical activity, smoking, and alcohol consumption in association with incidence of type 2 diabetes among middle-aged and elderly Chinese men," PLoS ONE, vol. 8, no. 11, Article ID e77919, 2013.

[7] I. Baik and C. Shin, "Prospective study of alcohol consumption and metabolic syndrome," The American Journal of Clinical Nutrition, vol. 87, no. 5, pp. 1455-1463, 2008.

[8] I. Wakabayashi, "Associations between heavy alcohol drinking and lipid-related indices in middle-aged men," Alcohol, vol. 47, no. 8, pp. 637-642, 2013.

[9] M. Cullmann, A. Hilding, and C.-G. Östenson, "Alcohol consumption and risk of pre-diabetes and type 2 diabetes development in a Swedish population," Diabetic Medicine, vol. 29, no. 4, pp. 441-452, 2012.

[10] I. Wakabayashi, "Influence of gender on the association of alcohol drinking with blood pressure," American Journal of Hypertension, vol. 21, no. 12, pp. 1310-1317, 2008.

[11] H. Schargrodsky, R. Hernández-Hernández, B. M. Champagne et al., "CARMELA: assessment of cardiovascular risk in seven Latin American Cities," American Journal of Medicine, vol. 121, no. 1, pp. 58-65, 2008.

[12] S. Zhu, M.-P. St-Onge, S. Heshka, and S. B. Heymsfield, "Lifestyle behaviors associated with lower risk of having the metabolic syndrome," Metabolism: Clinical and Experimental, vol. 53, no. 11, pp. 1503-1511, 2004.

[13] V. Soto, E. Vergara, and E. Neciosup, "Prevalencia y factores de riesgo de síndrome metabólico en población adulta del departamento de Lambayeque, Perú-2004," Revista Peruana de Medicina Experimental y Salud Pública, vol. 22, no. 4, pp. 254-256, 2005. 
[14] V. Bermúdez, R. P. Marcano, C. Cano et al., "The maracaibo city metabolic syndrome prevalence study: design and scope," American Journal of Therapeutics, vol. 17, no. 3, pp. 288-294, 2010.

[15] H. Méndez Castellano and M. C. de Méndez, "Estratificación social y biología humana: método Graffar modificado," Archivos Venezolanos de Puericultura y Pediatría, vol. 49, pp. 93-104, 1986.

[16] L. Baglietto, D. R. English, J. L. Hopper, J. Powles, and G. G. Giles, "Average volume of alcohol consumed, type of beverage, drinking pattern and the risk of death from all causes," Alcohol and Alcoholism, vol. 41, no. 6, pp. 664-671, 2006.

[17] C. A. Martín and C. P. Rojano, "Conceptos y anamnesis del consumo de alcohol en la consulta de Atención Primaria," Medicina General, vol. 29, pp. 957-962, 2000.

[18] H.-J. Im, S.-M. Park, J.-H. Choi, and E.-J. Choi, "Binge drinking and its relation to metabolic syndrome in Korean adult men," Korean Journal of Family Medicine, vol. 35, no. 4, pp. 173-181, 2014.

[19] V. Bermúdez, Y. Torres, V. Apuzzese et al., "Alcohol drinking patterns in the adult population from the Maracaibo municipality, Zulia-Venezuela," Revista Latinoamericana de Hipertensión, vol. 9, no. 3, pp. 21-28, 2014.

[20] Health Statistics, NHANES III Reference Manuals and Reports (CDROM), Centers for Disease Control and Prevention, Hyattsville, Md, USA, 1996, http://www.cdc.gov/nchs/data/ nhanes/nhanes3/cdrom/nchs/manuals/anthro.pdf.

[21] W. T. Friedewald, R. I. Levy, and D. S. Fredrickson, "Estimation of the concentration of low-density lipoprotein cholesterol in plasma, without use of the preparative ultracentrifuge.," Clinical Chemistry, vol. 18, no. 6, pp. 499-502, 1972.

[22] K. G. Alberti, R. H. Eckel, S. M. Grundy et al., "Harmonizing the metabolic syndrome: a joint interim statement of the International Diabetes Federation Task Force on Epidemiology and Prevention; National Heart, Lung, and Blood Institute; American Heart Association; World Heart Federation; International Atherosclerosis Society; and International Association for the Study of Obesity," Circulation, vol. 120, no. 16, pp. 16401045, 2009.

[23] H. S. Buttar, T. Li, and N. Ravi, "Prevention of cardiovascular diseases: role of exercise, dietary interventions, obesity and smoking cessation," Experimental and Clinical Cardiology, vol. 10, no. 4, pp. 229-249, 2005.

[24] F. B. Hu, "Globalization of diabetes: the role of diet, lifestyle, and genes," Diabetes Care, vol. 34, no. 6, pp. 1249-1257, 2011.

[25] Y.-W. Park, S. Zhu, L. Palaniappan, S. Heshka, M. R. Carnethon, and S. B. Heymsfield, "The metabolic syndrome: prevalence and associated risk factor findings in the US population from the Third National Health and Nutrition Examination Survey, 1988-1994," Archives of Internal Medicine, vol. 163, no. 4, pp. 427-436, 2003.

[26] I. Baik and C. Shin, "Prospective study of alcohol consumption and metabolic syndrome," American Journal of Clinical Nutrition, vol. 87, no. 5, pp. 1455-1463, 2008.

[27] M. T. Vicente-Herrero, M. V. R. I. de la Torre, L. M. Capdevilla García, A. A. López-González, and M. J. Terradillos García, "Consumo de alcohol en población trabajadora española y repercusiones metabólicas," Revista Cubana de Salud Pública, vol. 40, no. 1, 2014, http://www.bvs.sld.cu/revistas/spu/vol40_1_ 14/spu05114.htm.

[28] K.-W. Lee, B.-J. Park, H.-T. Kang, and Y.-J. Lee, "Alcoholdrinking patterns and metabolic syndrome risk: the 2007
Korean National Health and Nutrition Examination Survey," Alcohol, vol. 45, no. 5, pp. 499-505, 2011.

[29] I. Wakabayashi, "Cross-sectional relationship between alcohol consumption and prevalence of metabolic syndrome in japanese men and women," Journal of Atherosclerosis and Thrombosis, vol. 17, no. 7, pp. 695-704, 2010.

[30] M. S. Freiberg, H. J. Cabral, T. C. Heeren, R. S. Vasan, and R. C. Ellison, "Alcohol consumption and the prevalence of the metabolic syndrome in the U.S. A cross-sectional analysis of data from the Third National Health and Nutrition Examination Survey," Diabetes Care, vol. 27, no. 12, pp. 2954-2959, 2004.

[31] C. Chrysohoou, D. B. Panagiotakos, C. Pitsavos et al., "Effects of chronic alcohol consumption on lipid levels, inflammatory and haemostatic factors in the general population: the 'ATTICA' Study," European Journal of Cardiovascular Prevention and Rehabilitation, vol. 10, no. 5, pp. 355-361, 2003.

[32] K. Sun, M. Ren, D. Liu, C. Wang, C. Yang, and L. Yan, "Alcohol consumption and risk of metabolic syndrome: a meta-analysis of prospective studies," Clinical Nutrition, vol. 33, no. 4, pp. 596602, 2014.

[33] O. Clerc, D. Nanchen, J. Cornuz et al., "Alcohol drinking, the metabolic syndrome and diabetes in a population with high mean alcohol consumption," Diabetic Medicine, vol. 27, no. 11, pp. 1241-1249, 2010.

[34] C.-C. Chen, W.-Y. Lin, C.-I. Li et al., "The association of alcohol consumption with metabolic syndrome and its individual components: the Taichung community health study," Nutrition Research, vol. 32, no. 1, pp. 24-29, 2012.

[35] L. Jin, Y. Huang, Y. Bi et al., "Association between alcohol consumption and metabolic syndrome in 19,215 middle-aged and elderly Chinese," Diabetes Research and Clinical Practice, vol. 92, no. 3, pp. 386-392, 2011.

[36] G. Corrao, V. Bagnardi, A. Zambon, and C. La Vecchia, "A metaanalysis of alcohol consumption and the risk of 15 diseases," Preventive Medicine, vol. 38, no. 5, pp. 613-619, 2004.

[37] A. Buja, E. Scafato, G. Sergi et al., "Alcohol consumption and metabolic syndrome in the elderly: results from the Italian longitudinal study on aging," European Journal of Clinical Nutrition, vol. 64, no. 3, pp. 297-307, 2010.

[38] K. Shuval, C. E. Finley, K. G. Chartier, B. A. Balasubramanian, K. P. Gabriel, and C. E. Barlow, "Cardiorespiratory fitness, alcohol intake, and metabolic syndrome incidence in men," Medicine and Science in Sports and Exercise, vol. 44, no. 11, pp. 2125-2131, 2012.

[39] S. E. Brien, P. E. Ronksley, B. J. Turner, K. J. Mukamal, and W. A. Ghali, "Effect of alcohol consumption on biological markers associated with risk of coronary heart disease: systematic review and meta-analysis of interventional studies," British Medical Journal, vol. 342, article d636, 2011.

[40] I. Králová Lesná, P. Suchánek, P. Stávek, and R. Poledne, "May alcohol-induced increase of HDL be considered as atheroprotective?" Physiological Research, vol. 59, no. 3, pp. 407-413, 2010. 


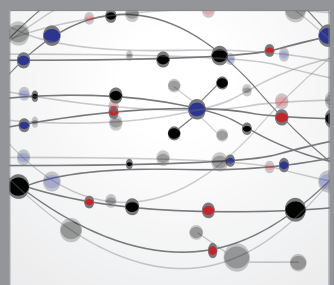

The Scientific World Journal
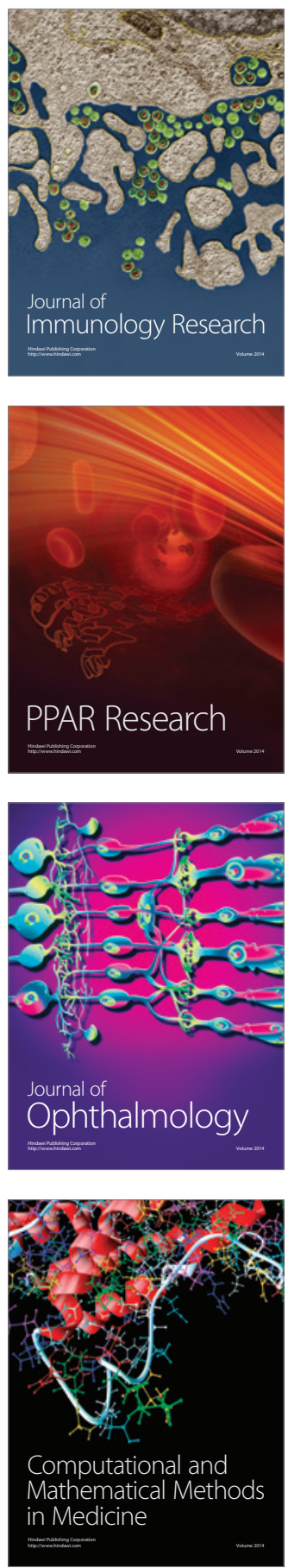

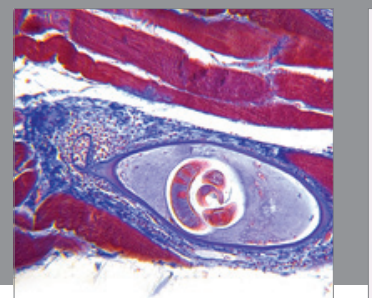

Gastroenterology

Research and Practice
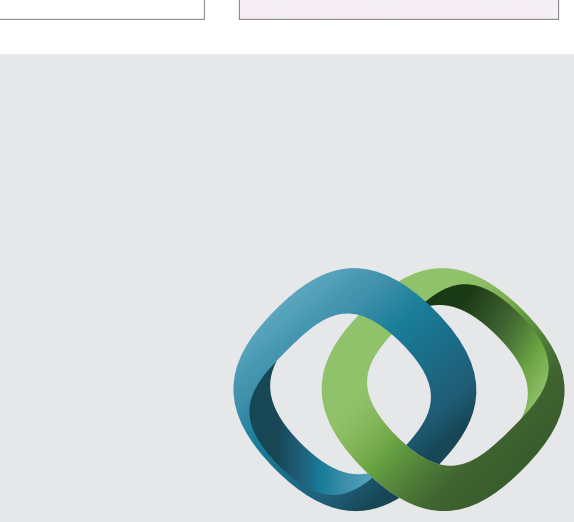

\section{Hindawi}

Submit your manuscripts at

http://www.hindawi.com
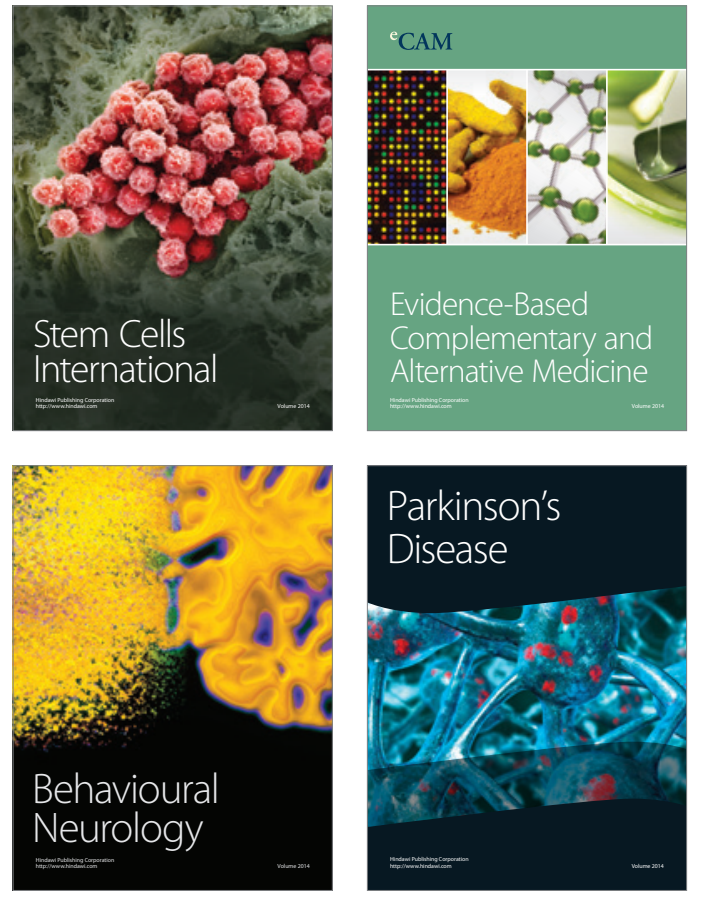
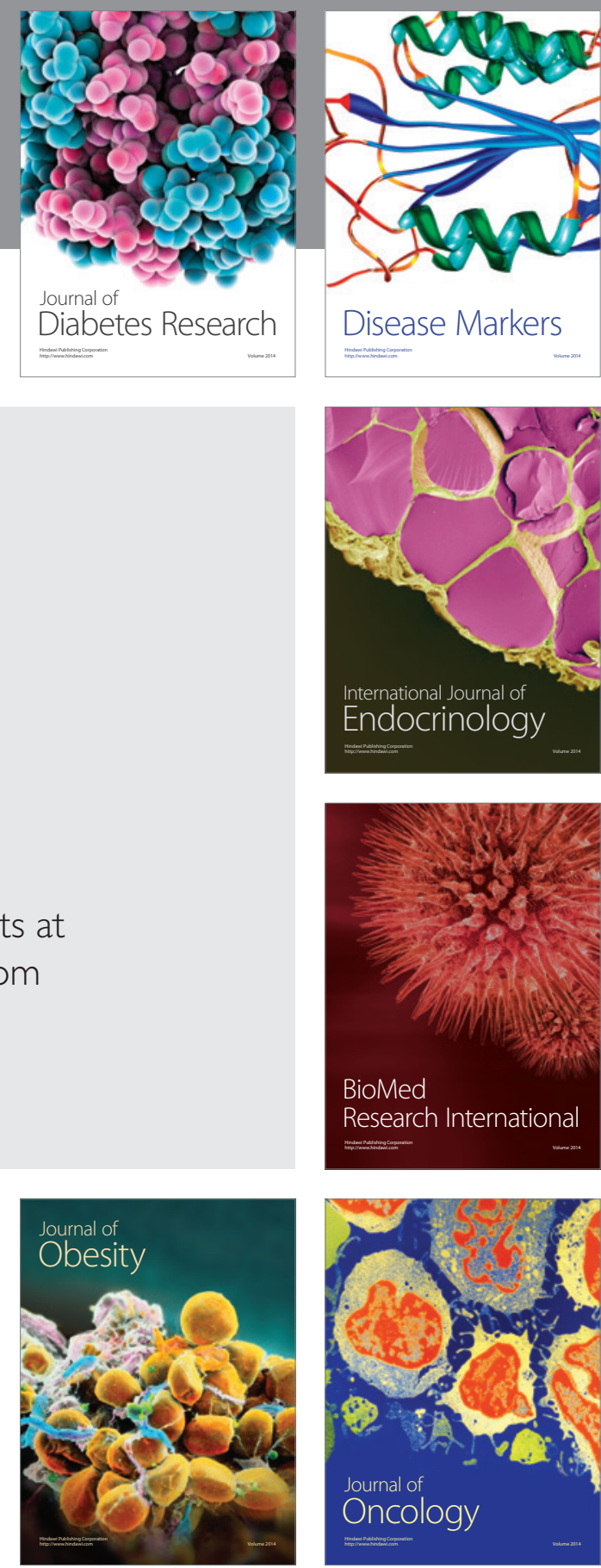

Disease Markers
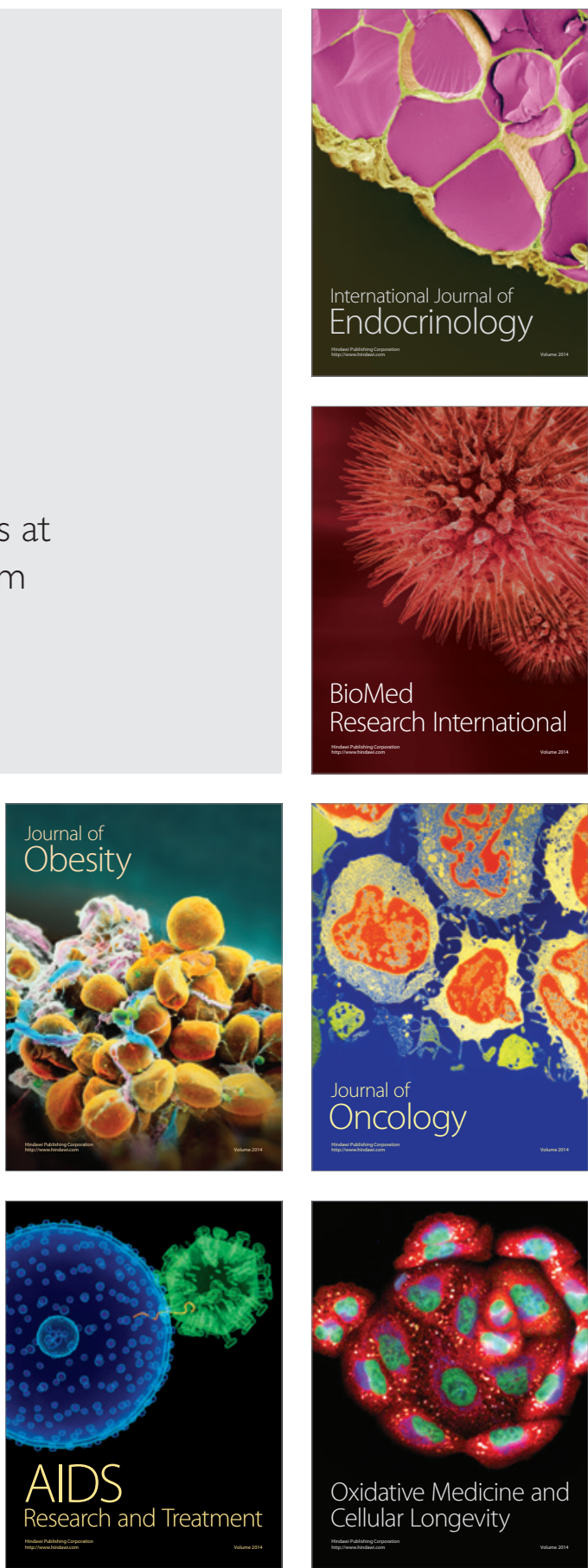